\title{
Teaching Strategies for Direct and Indirect Instruction in Teaching Engineering
}

\author{
http://dx.doi.org/ijep.v1i3.1805 \\ Tiia Rüütmann, Hants Kipper \\ Tallinn University of Technology \\ Estonian Centre for Engineering Pedagogy \\ Tallinn, Estonia
}

\begin{abstract}
It is important to select the proper instructional strategy for a specific learning outcome in teaching engineering. There are two broad types of learning outcomes: facts, rules and action sequences (on lower levels of complexity in the cognitive, affective and psychomotor domains), and concepts, patterns and abstractions (on higher level of complexity in the above named domains). Facts, rules and action sequences are taught using instructional strategies of direct instruction. Concepts, patterns and abstractions are taught using strategies of indirect instruction. Strategies of both types of learning may be combined, providing a menu of teaching strategies that help students solve problems, think critically and work cooperatively. This article presents teaching strategies suitable for direct and indirect instruction used in teaching engineering.
\end{abstract}

Index Terms-Teaching strategies; direct instruction; indirect instruction, engineering pedagogy.

\section{INTRODUCTION}

Have you ever wondered why some teachers are more liked than others? Students cannot wait to attend the classes of some teachers, but dread attending the classes of others.

Knowledge of a variety of instructional strategies and flexibility to change them within and among lessons are two of greatest assets a teacher can have. Just as the carpenter or electrician must select a proper tool for a specific task, a teacher must be able to select a proper instructional strategy for a specific learning outcome.

Students learn in various ways, and teachers should vary their use of instructional strategies so that they can relate to their learning styles and needs.

Even before instruction takes place, teachers should think about and make decisions concerning prerequisite knowledge of students, teaching content, instructional strategies, the use of instructional materials and technology, teaching techniques, classroom management and discipline, assessment of student learning, and a host of other related issues. During instruction, teachers must implement these decisions in a dynamic way. Decision making involves giving consideration to a matter, identifying the desired end result, determining the options to get to the end result and selecting the most suitable option to achieve the desired purpose. Teacher decisions will ultimately influence student learning.

\section{CATEGORIES OF TEACHING AND LEARNING}

One way to vary instruction is to use deductive and inductive instructional strategies. Deductive strategies are more direct and straightforward and lend themselves to direct instructional approaches, whereas inductive strategies are intended to tap into the interests and thinking abilities of the students, being more indirect.

Deductive strategies are instructional approaches that start with a known principle and then attention moves to the unknown. The strengths of the deductive strategy are the directness and specific focus of the teaching strategy, and the tight linkage between the teacher's examples and the task required of students. The lesson begins with known principles and then leads to examples of the new principle. It is a fairly direct straightforward way of addressing the lesson objective [1].

Inductive strategies are instructional approaches that start with and unknown principle and then attention moves to a known one. A teacher using an inductive approach may start a lesson with asking questions and using examples and thus helping students to recognize the principle being learned. This inductive approach is more indirect, but it can be very effective because students interact with the content to make meaning. Inductive strategies often begin with exploratory activities and lead to students discovering a concept or generalization.

Teachers should select the proper instructional strategy for a specific learning outcome [2]:

- Outcomes for teaching facts, rules and action sequences often represent behaviors at lower levels of complexity in the cognitive, affective and psychomotor domains. These include the knowledge, comprehension and application levels of the cognitive domain; the awareness, responding and valuing levels of the affective domain; and the imitation, manipulation and precision levels of the psychomotor domain;

- Outcomes for teaching concepts, patterns and abstractions represent behaviors at the higher levels of complexity in these domains. They include outcomes at the analysis, synthesis and evaluation levels of the cognitive domain; the organization and characterization levels of the affective domain; and the articulation and naturalization levels of the psychomotor domain.

Facts, rules and action sequences are most commonly taught using instructional strategies that emphasize knowledge acquisition (direct instruction), in a presentation-recitation format, involving large amount of teacher 
PAPER

TEACHING STRATEGIES FOR DIRECT AND INDIRECT INSTRUCTION IN TEACHING ENGINEERING

talk, questions and answers, review and practice, and the immediate correction of student errors [3].

Concepts, patterns and abstractions are most commonly taught using strategies that emphasize inquiry or problem solving (indirect instruction). Knowledge acquisition and inquiry are different types of learning outcomes, and each must be linked with specific strategies to reach the desired outcome. Both types of learning could be combined to provide a menu of teaching strategies that help students solve problems, think critically and work cooperatively.

\section{III.EFFECTIVE TEACHING STRATEGIES IN TEACHING ENGINEERING}

\section{A. Strategies for Direct Instruction}

Direct instructional strategies are academically focused with the teacher clearly stating the goals for the lesson. The teacher monitors student understanding and provides feedback to students on their performance.

Direct instruction has four key components:

- Clear determination and articulation of goals;

- Teacher-directed instruction;

- Careful monitoring of students' outcomes;

- Consistent use of effective classroom organization and management methods.

Direct instruction is effective because it is based on behavioralistic learning principles (obtaining students' attention, reinforcing correct responses, providing corrective feedback, and practicing correct responses), increasing the academic learning time during which students are attending to the task at a high success rate. Students learn basic skills more rapidly when they receive a greater portion of their instruction directly from the teacher [4].

Most students cannot stay focused throughout a lecture. After about 10-15 minutes their attention begins to drift, first for brief moments and then for longer intervals, and by the end of the lecture they are receiving very little and retaining less. A classroom research study has showed that immediately after a lecture students recalled $70 \%$ of the information presented in the first ten minutes and only $20 \%$ of that from the last ten minutes [2]. Students' attention can be maintained throughout a class session by giving them periodically something to do [5].

There is no sense to stop a lecture and wait for students' questions. More effective in teaching engineering is to involve students actively, thus finding out what the students have not understood and only then the teacher answers arisen questions. The wide array of effective active methods in lecture should wipe off the notion that good teachers are born and not made [6].

Once a teacher incorporates students' active breaks into the lecture, an interactive lecture is given, during which students are in some way interacting with the material for brief, controlled period of time. A teacher must carefully time-control the student-active breaks, thus keeping students focused on the task [7].

At Estonian Centre for Engineering Pedagogy several tested interactive methods, suitable for teaching engineering are taught to the future technical teachers. The students practice holding interactive lectures in seminars and workshops. The following most frequently used interac- tive teaching methods are taught during the study program:

- Pair and compare - students pair off with their neighbors and compare lecture notes filling in what they have missed, thus reviewing and processing reflectively the lecture content. Time: 2-3 minutes;

- Pair, compare and ask - additionally to the previous teaching method, students jot down questions on the lecture content, thus the material is reviewed and analyzed. Teacher answers the questions that students cannot answer themselves. Time: 3 minutes, plus time to answer students' questions;

- Periodic free-recall, with pare and compare optionstudents put away their lecture notes and write down the most important points of the lecture and questions they have, thus reviewing and processing reflectively the lecture content. Students may work individually or in pairs and answer each other's questions. Time 2-3 minutes, plus time for teacher to answer students' questions;

- Listen, recall and ask, then pair, compare and answer - students only listen to mini-lecture with no note-writing, then open notebooks and write down all major points they can recall and questions they have. They pair off and compare lecture notes and answer each-other's questions. This activity makes students to review and mentally process your lecture content. Time 3-4 minutes for note-writing, 2-4 minutes for pair fill-ins and question answering, plus time for teacher to answer remaining questions;

- Solve a problem - students solve a problem based on the lecture content it makes students to apply the lecture content, informing the teacher how they have understood. Time: 3 minutes for solving, 1-3 minutes to answer questions;

- Pair and discuss - students pair off and discuss an open ended question, in order to apply, analyze or evaluate the lecture material and synthesize it with the course material. Time: 3-10 minutes, plus 5 -10 minutes for discussion;

- Think-pair-share - teacher gives students an open question or a problem and asks them to think quietly, then to discuss with their neighbor and finally to share with the class;

- Students' teams achievement divisions - after a lecture students' teams receive a worksheet to discuss, complete and give oral presentation on results to others;

- Send a problem - each group of students write a question or a problem on a flashcard and write a right answer or a solution on the back. The card is passed to other groups which formulate their own answers and check them against that written on the back side, and write their alternative answers if necessary. At the end the original senders discuss alternative answers;

- The one-minute paper - students summarize the most important or useful points they learned from the lecture and questions that remained. It helps students think, absorb, digest, extrapolate and internalize new material moving it to long-term memory;

- The muddiest point - students give a quick response to a question: "What was not clear or confusing point 
in the lecture or topic?” They must identify and formulate what they did not understand. This method requires some higher-order thinking skills, ability to concentrate and pay attention;

- One-sentence summary - students summarize concisely, completely and creatively a large amount of information of the lecture or topic, thus developing abilities to synthesize, summarize and integrate ideas and information;

- Directed paraphrasing - develop students' ability to translate highly specialized information into everyday language paraphrasing a lesson compactly in their own words;

- Application cards - after students have heard or read about an important principle, theory etc index cards are handed out to write down at least one possible real-world application for what has been learned. The method develops ability to think creatively, to apply principles to a new problem and situation, to draw interferences from observation.

A well-known direct instruction approach, explicit teaching calls for the teacher to gain student attention, reinforce correct responses, provide feedback to students on their progress, and increase the amount of time that students spend actively engaged in learning course content. Its objective is to teach skills and help students to master a body of knowledge. Ten general principles apply when developing and explicit teaching lesson [2]:

- Begin a lesson with a short statement of goals;

- Begin a lesson with a short review of previous prerequisite learning;

- Present new material in small steps, with student practice after each step;

- Give clear and detailed instructions and explanations;

- Provide a high level of active practice for all students;

- Ask many questions, check for student understanding, and obtain responses from all students;

- Guide students during initial practice;

- Provide systematic feedback and corrections;

- Provide explicit instruction and practice for seatwork exercises, and when necessary, monitor students during seatwork;

- Continue practice until students are independent and confident.

Based on studies of explicit teaching, six teaching functions have been identified [1]:

- Daily review - to determine if students have obtained the necessary prerequisite knowledge or skills for the lesson;

- Presenting and structuring - effective teachers spend more time presenting new material and guiding practice than do less effective teachers, they also explain learning objectives to be covered, teach one point at a time and provide specific examples;

- Conducting guided practice - the purpose of which is to supervise initial practice of a skill and to provide reinforcement necessary to progress new learning from short-term into long-term memory;
- Providing feedback and correctives - providing students with an additional explanations and correct answers if necessary;

- Conducting independent practice - providing the additional review and reinforcement;

- Weekly and monthly review.

The following main strategies of direct instructions may be used in teaching engineering [3]:

- Presentations - should be used when objectives other than knowledge are sought; the information is detailed, abstract or complex; learner involvement is important; higher cognitive learning is sought, or students are below average ability; presentations are more effective when using interactive breaks;

- Demonstrations - involves a visual presentation to examine processes, information and ideas allowing students to observe real things and how they work;

- Questioning - is a critical instructional strategy [6];

- Recitations - determine if students remember or understand previously covered content with the teacher clearly in control of directing the learning;

- Practice and drills - going over the material just learned to consolidate, clarify and emphasize what has already been learned and repeating information on the topic until it is firmly established in students' minds;

- Guided practice and homework - teacher-directed strategy for the use of techniques through which students use and practice the knowledge and skills being addressed in the class, including seatwork, teacherled practice, student cooperative practice and homework;

- Review - an opportunity to look at the topic another time, not requiring drill techniques, being intended to reinforce the material learned;

When preparing a lesson plan, it is not enough to write a discussion plan. Teacher should select at least three discussion questions ahead that will advance student understanding. These key questions should guide meaningful discussion in the class, the questions should include words how, why, what if. Also teachers could ask students to explain their views by citing material from what has been covered in the class [6].

The direct instruction model is characterized by fullclass instruction by the organization of learning based questions, provision of detailed and redundant practice, by presentation of material. Direct instruction is most appropriate when the content in textbooks does not appear in appropriately sized piece, and when it is necessary to arouse student interest.

While using direct instruction, the teacher is clearly in control of the content or skill to be learned and the pace and rhythm of the lesson, introducing new skills or concepts in a relatively short period of time.

Direct instruction is limited to learning units of the content taught so they can be remembered and composing parts of the content learned into a whole, so that a rapid and automatic answer can occur. The task for the learner is simply to produce a response that mirrors the form and content of the stimulus. Learning at lower levels of the cognitive, affective and psychomotor domains relays 
heavily on remembering and composing, a great deal of teaching involves these simple processes.

\section{B. Strategies for Indirect Instruction}

Real-world activities, however often involve analysis, synthesis and decision-making behaviors in the cognitive domain, organization and characterization behaviors in the affective domain, and articulation and naturalization behaviors in the psychomotor domain. These behaviors are not learned by memorizing and rapidly and automatically reassembling them into a whole. Instead they must be constructed by learner's own attempts to use personal experiences and past learning to bring meaning to and make sense out of the content provided. Teaching for higher-order outcomes requires instructional strategies that represent the indirect instruction [7].

Indirect instruction is an approach to teaching and learning in which concepts, patterns and abstractions are taught in the context of strategies that emphasize concept learning, inquiry learning and problem-centered learning.

There are various ways to use indirect strategies: some have a higher degree of teacher-directed activities and others have students more actively involved in planning and designing instructional activities. In teaching engineering more commonly used indirect instructional strategies are inductive and social strategies.

More commonly used inductive instructional strategies in teaching engineering are:

- Concept attainment strategies - concepts serve as the building blocks for student higher-level thinking, being the main ideas used to help to categorize and differentiate information: comparisons, classifications, metaphors and analogies, using questions, drawing examples and non-examples in order to define the essential and nonessential attributes needed for making accurate generalizations;

- Inquiry lessons - inquiry, discovery and problemsolving approaches, being open-ended and creative way of seeking knowledge, consisting of following steps identify and clarity the problem, for hypotheses, collect data, brainstorm solutions, formulate questions, investigate, analyze and interpret the data to test hypotheses, discuss, reflect, draw conclusions, present results;

- Projects, reports, problems - project-based lessons flow in problem-solving environment where students work independently or cooperatively solving problems;

More common indirect social strategies used in teaching engineering are:

- Discussions - students learn when they participate, thinking out loud about concepts. The use of fullgroup discussions and small-group discussions improves student interactions. The best strategy in small-group discussions is to use think-pair-share method (teacher poses a question; students think individually; each students discusses his/her answer with a fellow student; students share their answers with the whole class) - students learn from one another;

- Students self-evaluation - engaging students in critical evaluation of their own responses and thereby taking responsibility for their own learning;
- Cooperative learning - involving students work together addressing specific instructional tasks, aiding and supporting each other;

- Simulations - student-directed activity placing students in situations that model a real-life environment requiring, assuming roles, making decisions, facing consequences.

The learner acquires information by transforming stimulus material into a response that requires students to rearrange and elaborate on the stimulus material. The process of generalization helps students classify differentappearing stimuli into the same categories on the basis of essential attributes.

The main instructional strategies of the inductive model in teaching engineering are: use of advance organizers (gives students a conceptual preview of what is to come and helps them store, label, package the content for retention and later use), conceptual movement (inductivedeductive), use of examples and non-examples (helping to define the essential and nonessential attributes needed for making accurate generalizations), use of questions (to guide students into discovering new dimensions of problem or new ways of resolving a dilemma), use of student ideas (to heighten student interest, tailor feedback, organize subject content around student problems, encourage positive attitudes toward the subject), student selfevaluation (to reason out their answers, comment and consider the accuracy of the responses), use of group discussion (involves student exchanges with successive interactions among a large number of students, helps to review, summarize and evaluate).

Generalization in indirect strategy is a process by which the learner responds in a similar manner to different stimuli, thereby increasing the range of instances to which particular facts, rules and sequences apply. By discrimination learner selectively restricts the acceptable range of instances by eliminating things that may look like the concept but differ from it on critical dimensions. The processes of generalization and discrimination together help students classify different-appearing stimuli into the same categories on the basis of essential attributes acting as magnets, drawing together all instances of a concept without the learner having to see or memorize all instances of it.

In indirect instruction the role of questions is to guide students into discovering new dimensions of a problem or new ways of resolving a dilemma. The use of questions during indirect instruction includes the following [5]:

- Refocusing;

- Presenting contradictions to be resolved;

- Probing for deeper more thorough responses;

- Extending the discussion to new areas;

- Passing responsibility to the class.

Inductive teaching methods suitable for teaching engineering (project-based, problem-based learning, and "justin-time" teaching) are taught in the teaching process of the master program for technical teachers at Estonian Centre for Engineering Pedagogy.

In problem-based learning students are confronted with an open-ended, real-world problem and work in teams to identify learning needs and develop a viable solution, with instructors acting as facilitators rather than primary 
sources of information. A well-designed problem guides students to use course content and methods, illustrates fundamental principles, concepts, and induces the students to infer those things for themselves instead of getting them directly from the instructor; thus engaging the students in the types of reflection and activities that lead to higher-order learning. Problem-based learning is not an easy teaching method to implement. It requires considerable subject expertise and flexibility on the part of instructors, who may be forced out of their areas of expertise [7].

Project-based learning begins with an assignment to carry out one or more tasks that lead to the production of the final product - a design, a model, a device or a computer simulation and is very suitable for engineering education. The culmination of the project is normally a written report summarizing the procedure used to produce the product and presenting the outcome.

There are three types of projects in engineering education that differ in the degree of student autonomy:

- Task project: student teams work on projects that have been defined by the instructor, using largely instructor-prescribed methods. This type of project provides minimal student motivation and skill development, and is part of traditional instruction in most engineering curricula.

- Discipline project: the instructor defines the subject area of the projects and specifies in general terms the approaches to be used (which normally involve methods common in the discipline of the subject area), but the students identify the specific project and design the particular approach they will take to complete it.

- Problem project: the students have nearly complete autonomy to choose their project and their approach to it.

A common difficulty faced by engineering students in a project-based environment is transferring methods and skills acquired in one project to another project in a different subject or discipline. Teachers educators should include such transference in their course objectives and should guide students to see connections between their current project and what they have learned previously, gradually withdrawing this support as the students become more adept at seeing the connections themselves. Teachers should also prepare students to fill in gaps in content knowledge when a need arises, taking into account the fact that such gaps may more likely arise in project-based learning than in conventional lecture-based instruction.

Just-in-time teaching [7] combines Web-based technology with active learning methods in the classroom. Students individually complete Web-based assignments before class in which they answer questions, the instructor reads through their answers before class and adjusts the lessons accordingly ("just in time"). The use of questions to drive learning makes the method inductive. It can be combined with almost any in-class active learning approach. The preliminary Web-based exercises normally require the student to preview the textbook material. The exercises are conceptual in nature and are designed to help students confront misconceptions they may have about the course material. They serve the functions of encouraging students to prepare for class regularly, helping teachers to identify students' difficulties in time to adjust their lesson plans, and setting the stage for active engagement in the classroom. Just-in-time teaching classes are a combination of interactive lectures, in which the instructor does a fair amount of mini-lecturing between activities and laboratories. In the lectures, the instructor might begin by summarizing student responses to the preparatory exercises and then discussing common errors. The collaborative recitations are likely to begin with a review of the homework, and then teams of students work on new problems [7]. Just-in-time teaching is widely used in teaching technical teachers at Estonian Centre for Engineering Pedagogy.

\section{Applying Induction and Deduction}

Both induction and deduction are important tools for concept learning, inquiry learning and problem-centered learning. But neither model need be used to the exclusion of the other. The teaching of concepts with the indirect instructional strategies uses inductive and deductive thinking to develop initially crude and overly restrictive concepts into more expansive and accurate understandings [8].

In Table I some examples of direct and indirect instruction have been presented.

Under direct instruction the objective is rapid attainment of facts, rules and action sequences. Content is divided into small, easily learned steps through the presentation, involving brief explanations, examples, practice and feedback. Both guided and independent practice help en-

TABLE I.

EXAMPLES OF OF DIRECT AND INDIRECT INSTRUCTION

\begin{tabular}{|c|c|}
\hline Direct Instruction & Indirect Instruction \\
\hline $\begin{array}{l}\text { Objective: To teach facts, rules } \\
\text { and action sequences }\end{array}$ & $\begin{array}{l}\text { Objective: To teach concepts, } \\
\text { patterns and abstractions }\end{array}$ \\
\hline $\begin{array}{l}\text { The teacher begins the lesson } \\
\text { with a review of the previous } \\
\text { day's work }\end{array}$ & $\begin{array}{l}\text { The teacher begins the lesson with } \\
\text { advance organizers that provide an } \\
\text { overall picture and allow for } \\
\text { concept expansion. }\end{array}$ \\
\hline $\begin{array}{l}\text { The teacher presents new } \\
\text { content in samll steps, provid- } \\
\text { ing explanations and examples }\end{array}$ & $\begin{array}{l}\text { The teacher focuses student } \\
\text { responses using induction and/or } \\
\text { deduction to refine and focus } \\
\text { generalizations }\end{array}$ \\
\hline $\begin{array}{l}\text { The teacher provides an oppor- } \\
\text { tunity for guided practice on a } \\
\text { small nuber oif sample prob- } \\
\text { lems and then prompts and } \\
\text { models when necessary to } \\
\text { attain } 60-80 \% \text { accuracy }\end{array}$ & $\begin{array}{l}\text { The teacher presents examples and } \\
\text { non-examples of the generaliza- } \\
\text { tions, identifying critical and } \\
\text { noncritical attributes }\end{array}$ \\
\hline $\begin{array}{l}\text { The teacher provides feedback } \\
\text { and correctives according to } \\
\text { whether the answer was cor- } \\
\text { rect, quick and firm; correct but } \\
\text { hesitant; incorrect due to } \\
\text { carelessness; or incorrect due to } \\
\text { the lack of knowledge }\end{array}$ & $\begin{array}{l}\text { The teacher draws additional } \\
\text { examples from student's own } \\
\text { experiences, interests and prob- } \\
\text { lems }\end{array}$ \\
\hline $\begin{array}{l}\text { The teacher provides an } \\
\text { opprtunity for independent } \\
\text { practice with seatwork and } \\
\text { strives for automatic responses } \\
\text { that are at least } 95 \% \text { correct }\end{array}$ & $\begin{array}{l}\text { The teacher uses questions to } \\
\text { guide discovery and articulation of } \\
\text { the generalization }\end{array}$ \\
\hline \multirow{2}{*}{$\begin{array}{l}\text { The teacher provides weekly } \\
\text { nad monthly reviews and re- } \\
\text { teaches unlearned content }\end{array}$} & $\begin{array}{l}\text { The teacher involves students in } \\
\text { evaluating their own responses }\end{array}$ \\
\hline & $\begin{array}{l}\text { The teacher promotes and moder- } \\
\text { ates discussion to firm up and } \\
\text { extend generalizations when } \\
\text { necessary }\end{array}$ \\
\hline
\end{tabular}


sure that students are actively engaged in the learning process at a high rate of success. Weekly and monthly reviews reinforce learned content and indicate what may need to be re-taught.

Table II illustrates the different steps involved in inductive versus deductive teaching.

Under indirect instruction, the objective is to teach concepts, patterns and abstractions with a problem, inquiry or concept-centered lesson. The teacher prepares for teaching high-order outcomes by providing an overall framework or content organization into which the lesson is placed, allowing for problem solutions, inquiry and concepts to be developed. Initially crude and inaccurate responses are gradually refined through induction and deduction, focusing on generalization of what is learned to some larger context. To accomplish this, both examples and nonexamples - some drawn from student interests and experiences - are used to distinguish essential from nonessential attributes. Throughout the teacher uses questions to guide students to inquire about and discover concepts and problem solutions and to evaluate their own responses. When the content is relatively unstructured, discussion groups may replace a more teacher-controlled format, and the teacher becomes a moderator:

- Orienting students to the objective of the discussion;

- Providing new or more accurate information where needed;

- Reviewing, summarizing or putting together opinions and facts into a meaningful relationship;

- Adjusting the flow of information and ideas to be most productive for the goals of the lesson;

- Combining ideas and promoting compromise to arrive at an appropriate consensus.

Direct and indirect instruction are often used together even within the same lesson. Teachers should not adopt one model to the exclusion of the other. Each contains a set of strategies that can compose an efficient and effective method for the teaching of facts, rules and sequences and to solve problems, inquire and learn concepts.

\section{TEACHING MODEL THAT WRKS}

Most professors begin teaching without so much as five minutes of training on how to do it. Even those who are genuinely concerned about their students and would like to be effective teachers automatically fall back on straight lecturing, which is the only instructional strategy most of them have ever seen. Although they work hard to make the course material as comprehensible and interesting as they can, many of them consistently see only glazed eyes during their lectures, terrible test grades, and evaluations suggesting that the students liked neither the course nor them. Some of them eventually figure out better ways to do their job; others never do, and spend their careers teaching ineffectively.

Teaching methods fostering active and long-term engagement with learning tasks emphasizing conceptual understanding are used in the study program for technical teachers at Estonian Centre for Engineering Pedagogy.

Teaching is a process being a subject to specific regularities and determined by a series of components throughout its course - teaching goals, teaching materials,
TABLE II.

COMPARISON OF INDUCTIVE AND DEDUCTIVE TEACHING

\begin{tabular}{|l|l|}
\hline \multicolumn{1}{|c|}{ Teaching Inductively } & \multicolumn{1}{|c|}{ Teaching Deductively } \\
\hline $\begin{array}{l}\text { The teacher presents specific } \\
\text { data from which a generaliza- } \\
\text { tion is to be drawn }\end{array}$ & $\begin{array}{l}\text { The teacher introduces the gener- } \\
\text { alization to be learned }\end{array}$ \\
\hline $\begin{array}{l}\text { Students are allowed uninter- } \\
\text { rupted time to observe or study } \\
\text { the data illustrating generaliza- } \\
\text { tioin }\end{array}$ & $\begin{array}{l}\text { The teacher reviews the task- } \\
\text { relevant prior facts, rules, and } \\
\text { action sequences needed to form } \\
\text { the generalization }\end{array}$ \\
\hline $\begin{array}{l}\text { Students are shown additional } \\
\text { examples and non-examples } \\
\text { supporting gerenalization }\end{array}$ & $\begin{array}{l}\text { Students raise a question, pose an } \\
\text { hypothesis or make prediction } \\
\text { thought to be supported by gener- } \\
\text { alization }\end{array}$ \\
\hline $\begin{array}{l}\text { Student attention is guided first } \\
\text { to the critical (relevant) aspects } \\
\text { of the data supporting the } \\
\text { generalization and thento the } \\
\text { noncritical (irrelevant) aspects }\end{array}$ & $\begin{array}{l}\text { Data, events, materials and objects } \\
\text { are gathered and observed to test } \\
\text { the prediction }\end{array}$ \\
\hline & $\begin{array}{l}\text { The results of the test are analyzed } \\
\text { and a conclusion is drawn as to } \\
\text { whether the prediction is sup- } \\
\text { ported by the data, events, materi- } \\
\text { als or subjects that were observed }\end{array}$ \\
\cline { 2 - 3 } $\begin{array}{l}\text { The starting generalization is } \\
\text { refined or revised in accordance } \\
\text { with the observations. }\end{array}$ \\
distinguishes the examples \\
from the non-examples
\end{tabular}

psychological structure, social structure, teaching media and teaching methods, all having a complex interdependent relationship [4]. Taking account of the named components a technical teacher can build up an effective model of engineering pedagogy for teaching engineering. Some strategies introduced below are used at Estonian Centre for Engineering Pedagogy in order to teach engineering more effectively.

Write comprehensive instructional objectives that list the things the students should be able to do (identify, explain, calculate, model, design, critique etc) to demonstrate that they have satisfactorily mastered the knowledge and skills the instructor wants them to master, including high-level thinking and problem-solving skills [5], [7], and [8].

Make the objectives available to the students. Design in-class activities and homework to provide practice in the desired skills, and make the tests specific instances of a subset of the instructional objectives [4], [5], [7], and [8].

Find out at the beginning of a course what most of the students know and don't know and what misconceptions they have about the subject - start teaching from that point [4].

Recognize that good students vary considerably in motivation, cultural background, interests, and learning style, and teach accordingly. Motivate learning - relate the material being presented to what has come before and what will to come in the same course, to material in other courses, and particularly to the students' personal experience [4], [5].

Provide a balance of concrete information (facts, data, real or hypothetical experiments and their results) and abstract concepts (principles, theories, and mathematical models), using both, deductive and inductive teaching. Balance material that emphasizes practical problemsolving methods with material that emphasizes fundamental understanding [3], [4], and [5]. 
Follow the scientific method in completing, structuring and presenting theoretical material. Provide concrete examples of the phenomena the theory describes or predicts then develop the theory or formulate the mod and show how the theory or mod can be validated, deduce its consequences and present applications [3], [4], and [5].

Use pictures, schematics, graphs, and simple sketches liberally before, during, and after the presentation of verbal material. Show films. Provide demonstrations, hands-on, if possible. Use suitable modern teaching media [3], [4], and [5].

Do not fill every minute of class time lecturing and writing on the board. Provide intervals - however brief for students to think about what they have been told [3], [5], and [7].

Provide opportunities for students to do something active besides transcribing notes, hold interactive lectures. Small-group activities that take no more than five minutes are extremely effective for this purpose [3], [7].

In addition to interactive lecturing, have students work individually and in small groups on brief course-related activities, such as answering questions, setting up problem solutions, completing steps in derivations, interpreting observations or experimental data, estimating, predicting, brainstorming, troubleshooting. Call on several students for responses at the conclusion of each activity then invite volunteers to provide more responses to open-ended questions, and proceed with the lesson when the desired points have been made. This is active learning [3], [6], and [8].

Assign some drill exercises to provide practice in the basic methods being taught. Also provide some openended problems, questions and exercises that call for analysis, synthesis and evaluation [5], [7], and [8].

Recognize that students learn best when they perceive a need to know the material being taught. Start with realistic complex problems, let students establish what they know and what they need to find out, and then guide them in finding it out by providing a combination of resources (which may include interactive mini-lectures and integrated hands-on or simulated experiments) and guidance on performing library and Internet research. This is inductive teaching and has a number of variations, including problem-based learning, project-based learning, guided inquiry, discovery learning, and just-in-time teaching [1], [2].

Supplement the traditional content with training in critical and creative thinking, methods of solving openended multidisciplinary problems (which tend to be what practicing engineers spend most of their time dealing with) [2], [3], and [4].

Talk to students about different learning styles, both in advising and in classes. Students are reassured to find their academic difficulties may not all be due to personal inadequacies [8].

Although the diverse styles with which students learn are numerous, the inclusion of a relatively small number of described techniques as an instructor's teaching tools should be sufficient to meet the needs of most or all of the students in any engineering class. The techniques and suggestions presented above should serve this purpose in any case.

Assign a combination of individual work and teamwork, structuring the latter to provide assurances of indi- vidual accountability for all the work done and following other procedures known to promote good teamwork skills (including communication, leadership, project management, time management, and conflict resolution skills). This is cooperative learning [1], [2].

At Estonian Centre for Engineering Pedagogy cooperative learning is used. Cooperative learning is an instructional approach in which students work in teams on a learning task structured to have the following features [1], [3], and [7]:

- Positive independence - there must be a clearly defined group goal (complete the problem set, write the lab report, design the process) that requires involvement of every team member to achieve. If anyone fails to do his/her part, everyone is penalized in some manner;

- Individual accountability - each student in the team is held responsible for doing his/her share of the work and for understanding everyone else's contribution;

- Face-to-face interaction - although some of the group work may be parceled out and done individually, some must be done interactively, with team members providing one another with questions, feedback, and instruction;

- Appropriate use of interpersonal and teamwork skills - students should be helped to develop leadership, communication, conflict resolution, and time management skills;

- Regular self-assessment of team functioning - teams should periodically be required to examine what they are doing well together and what areas need improvement.

Cooperative learning exercises may be performed in or out of class. Common tasks for cooperative learning groups in engineering are completing laboratory reports, design projects, and homework assignments in lecture courses.

Once a class accustomed to group work gets started on a problem, the classroom atmosphere is transformed: discussions, arguments, and occasional laughter can be heard, all sounds of learning taking place. Even students who may not be doing much talking are engaged in thinking about the question at hand instead of just mechanically transcribing notes. Just five minutes of activities in a 50minute class can be enough to keep the students awake and attentive for the remaining 45 minutes of lecturing.

\section{CONCLUSION}

When used with the appropriate content and purpose, direct and indirect instruction can significantly improve teaching effectiveness. Although both models of instruction are significant contributions to teaching and learning, neither should exclusively dominate the instructional style in teaching engineering. It would be unfortunate if teaching exemplified only the direct model or the indirect model as the original purpose of introducing these models is to increase the instructional strategies in teaching engineering.

These models and their strategies provide a variety of instructional tools that could be used in many combinations to match teacher's particular objectives and students. 
Just as different entrees have prominent and equal places on a menu, so should the direct and indirect models have prominent and equal places in teaching engineering. Teachers should alternately employ both, the direct and indirect instruction to create tantalizing combinations of educational flavors for the students.

Professional-level teaching is both an art and a science. Like an artist, a good technical teacher makes decision from both a technical and a creative perspective. Professional technical teachers develop their science by using carefully-planned, fine-tuned lessons that reflect an understanding of many different teaching techniques. They develop artistry by being aware of what they are doing, and how it affects their learners. They are constantly aware that the choices they make affect the intellectual, attitudinal and psychomotor skills of their students. Above all, they make decisions.

\section{REFERENCES}

[1] Burden P.R.; Byrd D.M., A.B.: Methods for Effective Teaching, Meeting the needs of All Students, Pearson Education, 2010, 377 p.

[2] Borich G.: Effective Teaching Methods, Research-Based Practice, $7^{\text {th }}$ ed., Pearson Education, 2011, 477 p.
[3] Eggen P.D; Kauchak D.P.: Strategies and Models for Teachers, Teaching Content and Thinking Skills, Pearson Education, 2006, $376 \mathrm{p}$.

[4] Melezinek A., Ingenieurpädagogik. "Praxis der Vermittlung technischen Wissens”, Springer, 1999, 237 p.

[5] Orlich D.C.; Harder R.J.; Callahan R.C.: Teaching Strategies - A Guide of Effective Instruction, Houghton Mifflin Company, 2007, 384 p.

[6] Rüütmann T; Kipper H.: Strategies and Techniques of Questioning Effectuating Thinking and Deep Understanding in Teaching Engineering at Estonian Centre for Engineering Pedagogy, Problems of Education in 21th Century, vol 19, pp 36 - 45, 2010.

[7] Felder, R. M., "Inductive Teaching and Learning Methods: Definitions, Comparisons and Research Bases”, Journal of Engineering Education. 95 (2), pp 123-138, 2006.

[8] Felder, R. M., "Teaching Engineering in the 21st Century with a 12th-Century Model: How Bright is that?”. Chemical Engineering Education, 40(2), 110-113, 2006.

\section{AUTHORS}

Tiia Rüütmann and Hants Kipper are with Tallinn University of Technology, Estonian Centre for Engineering Pedagogy, Tallinn, Estonia.

Received 30 August 2011. Published as resubmitted by the authors 26 August 2011. 